\title{
Convective and conductive selection criteria of a stable dendritic growth and their stitching
}

\author{
Liubov Toropova ${ }^{1}$, Dmitri Alexandrov ${ }^{1}$, and Peter Galenko ${ }^{2}$ \\ ${ }^{1}$ Ural Federal University named after the first President of Russia B N Yeltsin \\ ${ }^{2}$ Friedrich-Schiller-Universitat Jena
}

July 18, 2020

\begin{abstract}
The paper deals with the analysis of stable thermo-solutal dendritic growth in the presence of intense convection. The n-fold symmetry of crystalline anisotropy as well as the two- and three-dimensional growth geometries are considered. The steadystate analytical solutions are found with allowance for the convective-type heat and mass exchange boundary conditions at the dendritic surface. A linear morphological stability analysis determining the marginal wavenumber is carried out. The new stability criterion is derived from the solvability theory and stability analysis. This selection criterion takes place in the regions of small undercooling. To describe a broader undercooling diapason, the obtained selection criterion, which describes the case of intense convection, is stitched together with the previously known selection criterion for the conductive-type boundary conditions. It is demonstrated that the stitched selection criterion well describes a broad diapason of experimental undercoolings.
\end{abstract}

\section{Hosted file}

Gen sel crit.pdf available at https://authorea.com/users/343926/articles/470546-convectiveand-conductive-selection-criteria-of-a-stable-dendritic-growth-and-their-stitching 